\title{
Optimizing Conditions for Spheroid Formation of Dental Pulp Cells in Cell Culture
}

\author{
YAJIE ZHENG ${ }^{1}$, LI JIANG ${ }^{1}$, MING YAN ${ }^{1}$, MARTIN GOSAU ${ }^{1}$, RALF SMEETS ${ }^{1}$, \\ LAN KLUWE ${ }^{1,2}$ and REINHARD E. FRIEDRICH ${ }^{1}$ \\ Departments of ${ }^{1}$ Oral and Craniomaxillofacial Surgery, and ${ }^{2}$ Neurology, \\ University Hospital Hamburg-Eppendorf, Hamburg, Germany
}

\begin{abstract}
Background/Aim: Spheroid formation is a wellknown feature of stem/progenitor cells. Dental pulp cells (DPCs) cultured in serum-free medium can also form spheroids. However, the success rate varies largely depending on various factors. This study aimed to explore these factors and optimize the conditions. Materials and Methods: Primary DPCs were obtained from 6 wisdom teeth. Possible influencing factors including donor teeth, concentrations of the KnockOut Serum Replacement (KSR), seeding density (regarding surface and volume), passage and freezing were tested. Results: DPCs from all 6 donor teeth formed spheroids in serum-free medium. Number, size, and total area of spheroids varied among different donor teeth. Optimal concentration of the KSR and seeding densities also varied from tooth to tooth. Generally, high KSR and high cell density lead to better spheroid formation. However, very high KSR and cell density can also lead to cell death and the fusion of spheroids to irregular aggregates. Conclusion: An initial setting can be recommended as: Serum-free MEM plus 10-15\% KSR and seeding densities of $1-2 \times 10^{5}$ cells $/ \mathrm{ml}$ and $2 \times 10^{5}$ cells $/ \mathrm{cm}^{2}$. These parameters provide a direction for optimizing the condition for obtaining spheroids from human DPCs.
\end{abstract}

Human dental pulp cells (DPCs) contain cells with stem/progenitor cell features that exhibit the potential to differentiate into multiple cell lineages (1-3). Dental pulp tissues can be easily obtained from extracted teeth, for

This article is freely accessible online.

Correspondence to: Reinhard E. Friedrich, Department of Oral and Craniomaxillofacial Surgery, Building O10, University Medical Center Eppendorf, Martinistrasse 52, 20246 Hamburg, Germany. Tel: +49 40741053259, Fax: +49 40741055467, e-mail: r.friedrich@uke.de

Key Words: Dental pulp, stem cell, spheroid formation, serum-free culture, osteogenic differentiation, adipose differentiation. example, wisdom teeth. They, therefore, provide a promising resource for application in regenerative medicine.

Cell-spheroid is a 3-dimension (3D) organization of cells. In real life, spheroid formation is the beginning of embryo development. Under certain conditions in culture, cells remain or migrate together and form a round sphere-like structure. However, not all cells can form spheroids, rather the ability of spheroid formation is a feature of stem/progenitor cells. A previous study (4) reported that DPCs can form spheroids when cultured under serum-free conditions. They reported stem cells in the core of spheroids and an increasing population of stem cells with time (4). These results suggested that $3 \mathrm{D}$ spheroid culture may provide a strategy for isolating and enriching the stem-like cell population from heterogeneous DPCs. Besides, spheroids provide a scaffold-free and serum-free strategy for maintaining cells in a more natural 3D organization, which is advantageous for developing medical applications.

However, applying the method of Xiao et al. (4), we could not reliably obtain spheroids. We often observed that some spheroids detach from the surface and die out. Also, some details, such as optimal cell density, are lacking. For studies designing to use DPCs in spheroids, it is helpful to optimize the conditions comprehensively for higher reliability and reproducibility. The present study was carried out to study possible factors which are expected to influence spheroid formation: 1) donor teeth, 2) concentrations of the Knockout Serum Replacement (KSR), 3) seeding density (regarding surface and volume), 4) passage and 5) freezing/thawing.

\section{Materials and Methods}

Culturing dental pulp cells. Primary DPCs were derived from 9 wisdom teeth, Z1 through Z9, of healthy donors (16-18 years old) who underwent extraction at the Department of Oral and Maxillofacial Surgery in Hamburg. This kind of specimen was usually disposed as biological waste. With the written consent of the patients, the teeth were anonymized and used for the study. The study protocol was reported to the Hamburg authority of privacy protection. The tumor cells S462 used in the study as control were established in our laboratory $(5,6)$. 

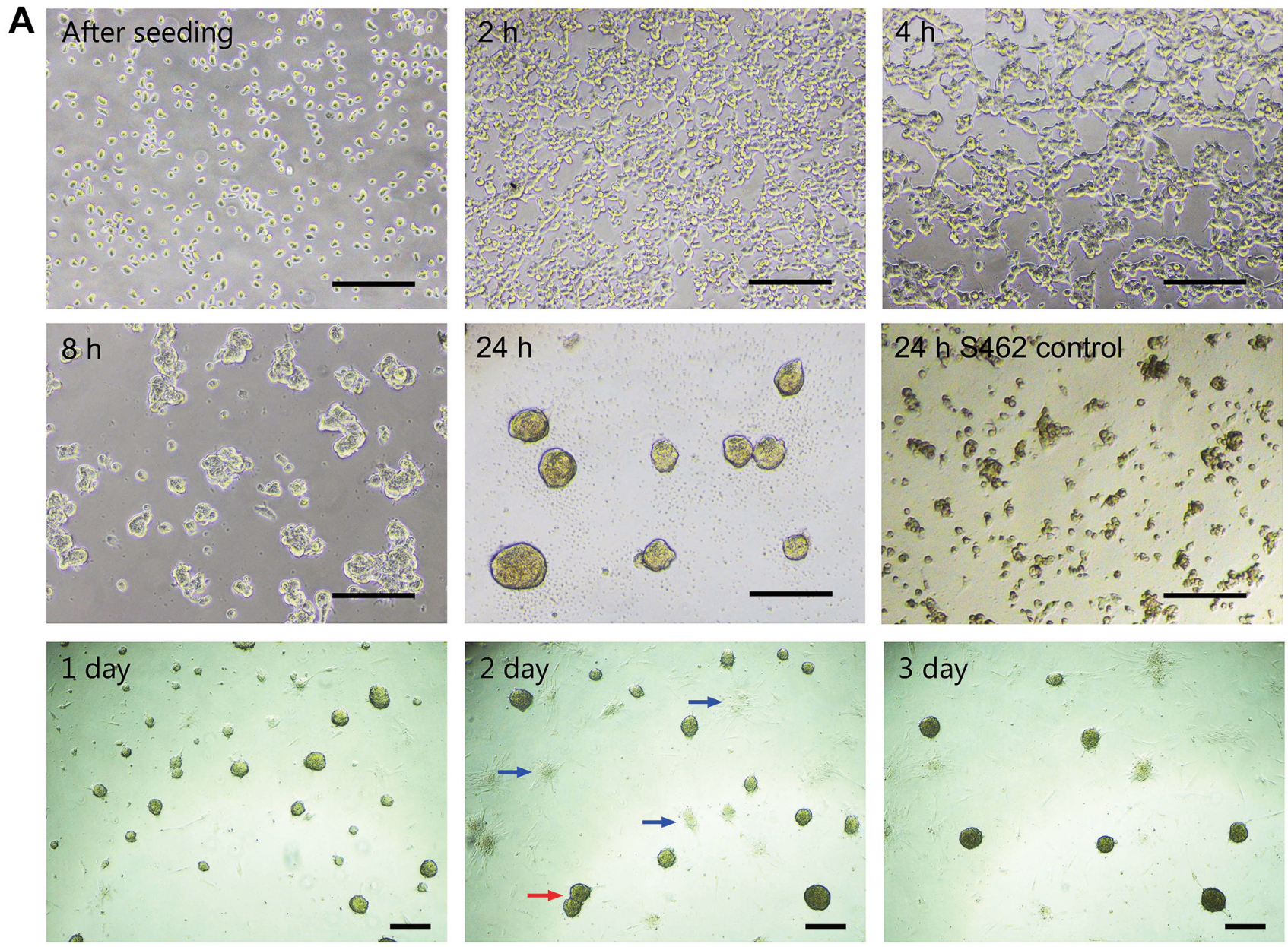

B
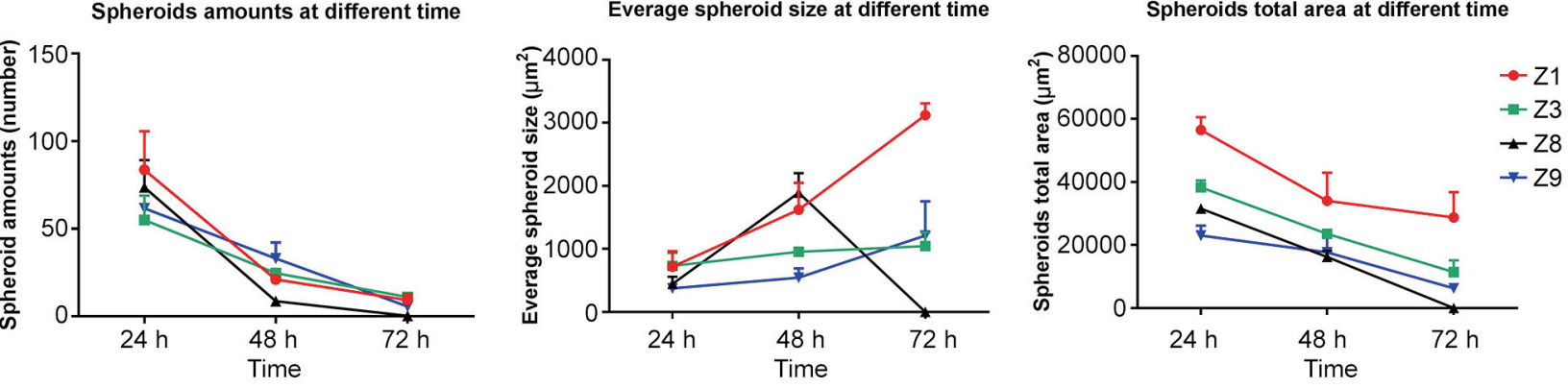

Figure 1. Dynamics of spheroid formation. A: Photos of spheroid formation at various time points. Scale bars=100 $\mu m$. Red arrow: spheroids fusing together; Blue arrows: spheroids falling apart and disappearing. No spheroid formation was observed for the cells of the tumor line S462 (2nd row, rightmost). B: Spheroids number, size and area of pulp cells from 4 different teeth on days 1, 2 and 3.

The extracted teeth were kept in sterile phosphate-buffered saline and transported into the laboratory where they were broken under a sterile environment by a hammer. The pulp tissues were gently separated from the teeth and cut into 2-3 $\mathrm{mm}^{3}$ pieces. These fragments of pulp tissues were let attach to the culture surface and incubated in Minimum Essential Medium (MEM) (Gibco, Grand Island, NY, USA) with $15 \%$ fetal bovine serum, $1 \%$ penicillin-streptomycin, and $1 \%$ Amphotericin B
(Gibco). After 7-10 days, DPCs started to migrate out of the tissue pieces and grow in monolayer. Pulp cells from 6 different wisdom teeth $(\mathrm{Z} 1,3,6,7,8,9)$ at passages 3-6 were used for the spheroid formation.

Spheroid formation. Cells were seeded at various densities and cultured in MEM with various concentrations of KnockOut ${ }^{\mathrm{TM}}$ Serum Replacement (KSR) (Gibco) as presented below. 
- Concentrations of KSR (\%): 0, 5, 10, 15

- Volume cell density $\left(10^{5} / \mathrm{ml}\right): 1 \times, 2 \times, 2.5 \times, 5 \times$

- Surface cell density $\left(10^{5} / \mathrm{cm}^{2}\right): 0.5 \times, 1 \times, 1.5 \times, 2 \times$

- Freezing/thawing: Frozen at $-80^{\circ} \mathrm{C}$ for one week. Then cultured in $15 \% \mathrm{KSR}$, at $1 \times 10^{5} \mathrm{cells} / \mathrm{ml}$ and of $2 \times 10^{5}$ cells $/ \mathrm{cm}^{2}$.

- Passage: Passages 3 and 6 were compared in $15 \% \mathrm{KSR}$, at $1 \times 10^{5}$ cells $/ \mathrm{ml}$ and of $2 \times 10^{5}$ cells $/ \mathrm{cm}^{2}$.

Spheroid formation was examined under microscope 1,2 and 3 days after the seeding. The number and size of the spheroids were recorded. Only spheroids meeting the following criteria are considered as DPC spheroids: 1) sphere-like form with a smooth surface, 2) the main body is translucent and 3) diameter larger than $10 \mu \mathrm{m}^{2}$. Spheroid size, number, and total area were calculated by Image J (Rasband, W.S., ImageJ, U. S. National Institutes of Health, Bethesda, MD, USA).

Osteogenic and adipogenic differentiation. For osteogenic and adipose tissue differentiation, additive cocktails $(0.1 \mu \mathrm{M}$ dexamethasone, $50 \mu \mathrm{M} \mathrm{L}$-ascorbic acid 2-phosphate, $10 \mathrm{mM} \beta$ glycerol phosphate) and (1 $\mu \mathrm{M}$ dexamethasone, $0.5 \mathrm{mM}$ IBMX, 0.2 $\mathrm{mM}$ indomethacin, $10 \mu \mathrm{M}$ insulin) were added, respectively. The media for DPCs in monolayer or in 3-days spheroids were changed to the above induction media or control media that did not have the additives. Media were changed every 3 days. After 21 days and 14 days of induction, calcium deposits and lipid droplets were stained with Alizarin red and Oil Red O, respectively.

\section{Results}

Primary DPCs in culture. From 6 out of the total of 9 healthy wisdom teeth, vital and well-growing pulp cells were obtained, corresponding to a success rate of $67 \%$. These six cultures were used for the following experiments. From the other 3 teeth, no vital cells were obtained in two cases and the cells grew very slowly in one case.

Dynamics of spheroid formation. Two hours after seeding in spheroid induction medium, DPCs started to aggregate (Figure 1A). They first formed a network structure which became increasingly thicker and approximately $4 \mathrm{~h}$ after seeding, the nets-structure started to break. Approximately eight hours after seeding, the breaking down of the network structure was completed and cell-aggregations of irregular forms appeared. One day after seeding, round spheroids with smooth boundaries and translucent bodies became visible. Later, some of the spheroids fused together and formed larger spheroids, while some others fell apart and disappeared (Figure 1A).

No spheroids were formed by the tumor cells MPNST 462, which were included as a comparison (Figure 1A, 2nd row, rightmost).

Spheroids were evaluated 1,2 and 3 days after seeding. Only those with nearly round form, translucent bodies, smooth boundaries and larger than $10 \mu \mathrm{m}^{2}$ in diameter were defined as spheroids. Generally, the size of spheroids increased with time while the numbers of spheroids
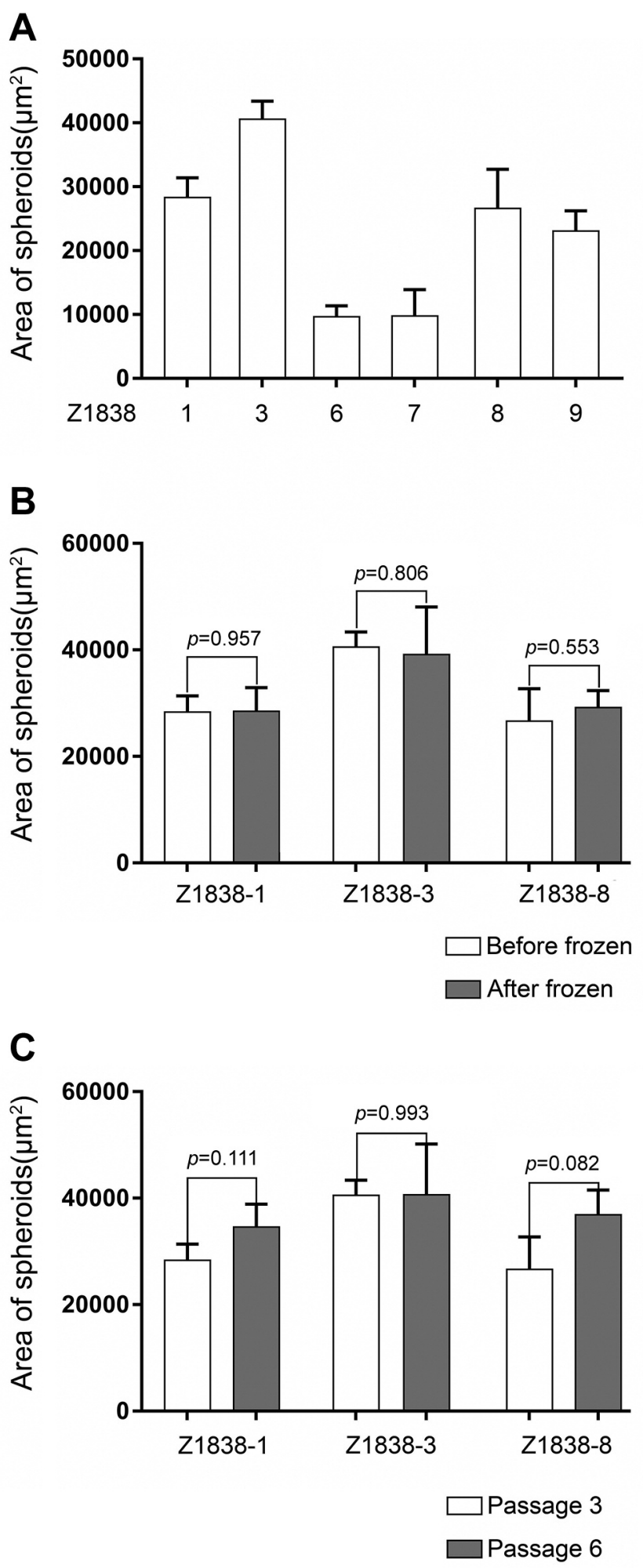

Figure 2. The ability of spheroids formation from different sources of DPCs varied (A). Freezing and passage up to 6 do not influence spheroid formation. The total area of spheroids was compared for cells with and without freezing/thawing $(B)$, and cells from passage 3 and 6 (C). Data are expressed as mean \pm standard deviation of 3 replicates. 

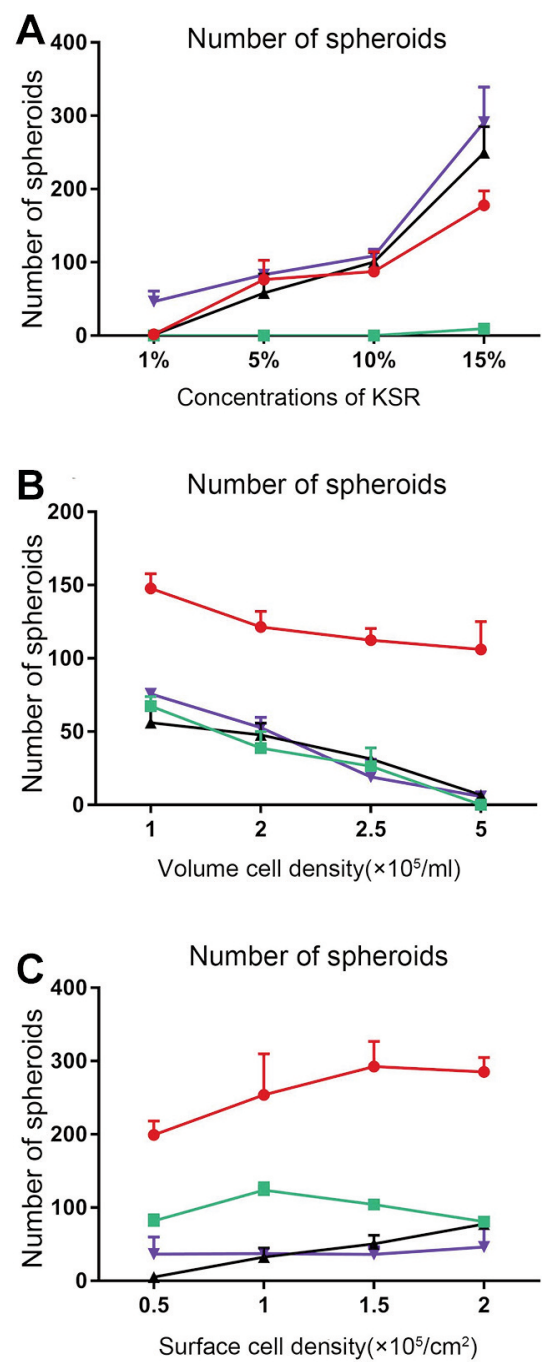
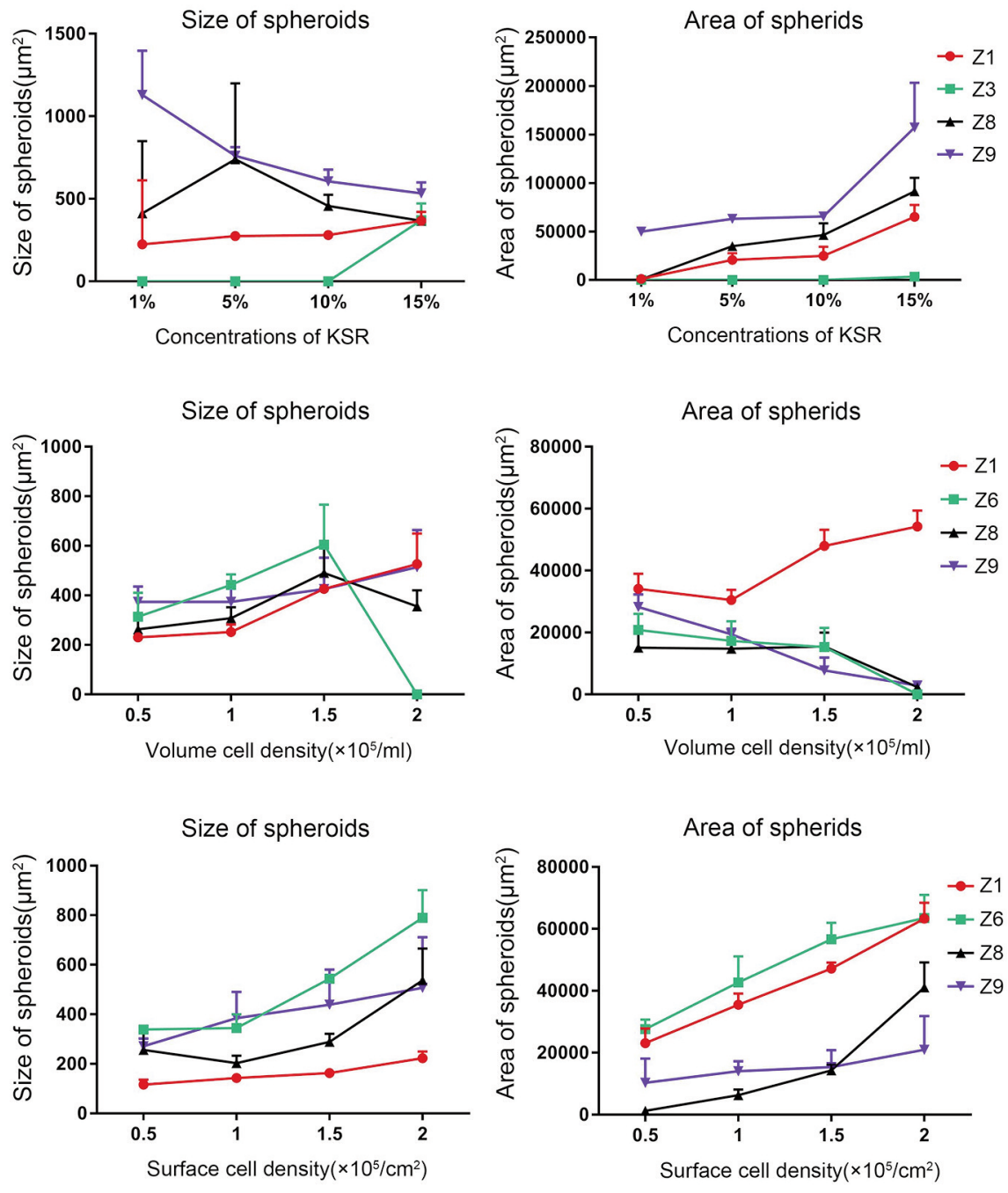

Figure 3. Factors influencing number (left), size (middle) and total area (right) of spheroids. A: KnockOut serum replacement concentration. B: seeding density in volume. $C$ : seeding density in area. Data are expressed as mean \pm standard deviation from 3 replicates.

decreased. The total area of the spheroids (size $\times$ number) decreased from day 1 to day 3 (Figure 1B). In one case (Z8), all spheroids disappeared on the third day. Decreasing of the number and total area of spheroids seem to be a result of losing activity of the KSR since after refreshing the medium, the number and size of all spheroids was maintained.

Spheroid formation varied among cells from different donor teeth. After $24 \mathrm{~h}$ of culture in the spheroid formation medium, cells from all 6 teeth formed spheroids. No spheroids were formed in the control of tumor cells. The area of the spheroids varied largely from tooth to tooth (Figure 2A).

Effect of KnockOut serum replacement concentration on spheroid formation. Generally, higher KSR concentration correlated with a larger number of spheroids (Figure 3A). By contrast, the size of the spheroids seemed to be less affected.

On the other side, in media with $>15 \%$ KnockOut, spheroids detached from the surface and died several days later in some cases.

Effect of seeding density on spheroid formation. Density in volume. KnockOut concentration was fixed to $15 \%$ and the cell density in the area was fixed at $2 \times 10^{5}$ cells $/ \mathrm{cm}^{2}$. Spheroids were evaluated one day after seeding. Among seeding densities of $1,2,2.5$ and $5 \times 10^{5}$ cells $/ \mathrm{ml}$, the largest number of spheroids was obtained at the lowest density $1 \times 10^{5}$ cells $/ \mathrm{ml}$ while only few spheroids were formed at the highest density $\left(5 \times 10^{5}\right.$ cells $\left./ \mathrm{ml}\right)$. In one case (Z6), no spheroids were formed at $5 \times 10^{5}$ cells $/ \mathrm{ml}$ (Figure 3B). In 


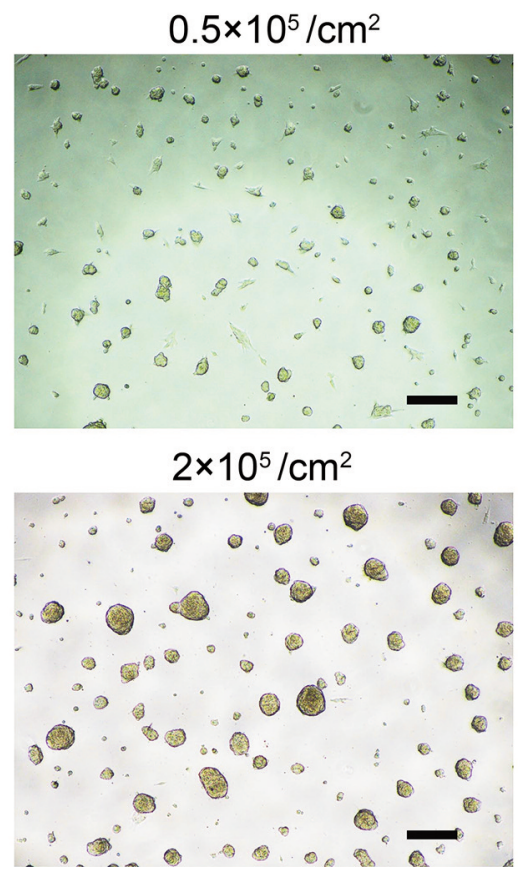

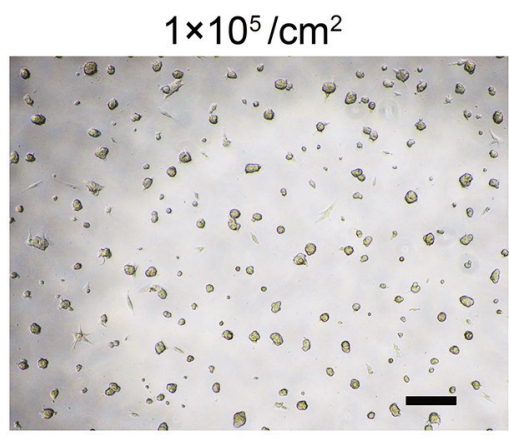

$2.5 \times 10^{5} / \mathrm{cm}^{2}$

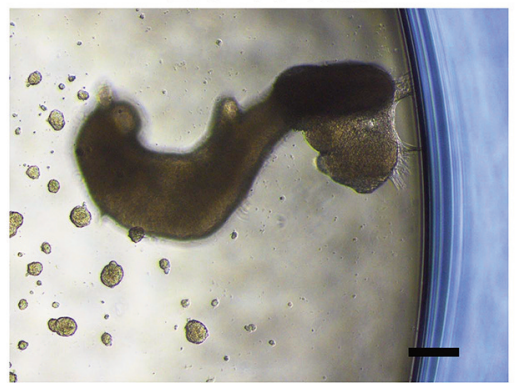

$1.5 \times 10^{5} / \mathrm{cm}^{2}$
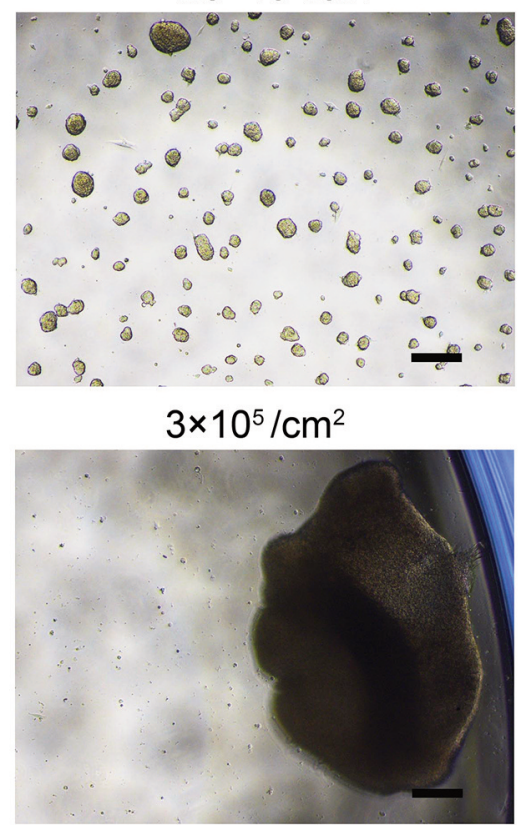

Figure 4. An example of the impact of surface density on spheroid formation. The size of spheroids increases with increasing density up to $2 \times 10^{5}$ cells $/ \mathrm{cm}^{2}$. However, at higher density $\left(2.5\right.$ and $3 \times 10^{5}$ cells $\left./ \mathrm{cm}^{2}\right)$, some spheroids fuse together, resulting in aggregates in irregular form. Scale bars $=100 \mu \mathrm{m}$.

concordance, spheroid size increased with increasing density. The area (size $\mathrm{x}$ number) of spheroids decreased in 3 cases and increased in one case (Figure 3B).

Density in area. KnockOut concentration was fixed to $15 \%$ and the cell density in volume was fixed at $1 \times 10^{5}$ cells $/ \mathrm{ml}$. Among the densities of $0.5,1,1.5$ and $2 \times 10^{5}$ cells $/ \mathrm{cm}^{2}$, the number of spheroids did not change substantially (Figure 3C). The size and area of the spheroids both increased with increasing density. However, density higher than $2 \times 10^{5}$ cells $/ \mathrm{cm}^{2}$ led to the fusion of spheroids in one case (Figure 4).

Effect of freezing and passaging on spheroid formation. The KnockOut concentration was fixed to $15 \%$ and seeding densities at $1 \times 10^{5}$ cells $/ \mathrm{ml}$ and $2 \times 10^{5}$ cells $/ \mathrm{cm}^{2}$. No clear effect was observed from freezing and thawing on the ability of the DPCs to form spheroids (Figure 2B). No clear effect of cell passages between 3 and 6 was detected regarding their spheroid formation (Figure 2C).

Differentiation potential of dental pulp cells in spheroids. The spheroid formation is a well-known feature of stem/progenitor cells. Therefore, DPCs in the form of spheroids may have stronger features or have a higher proportion of such stem/progenitor cells. To test this hypothesis, osteogenic and adipose tissue differentiation were compared between DPCs in spheroids and those in monolayer.
Since the differentiation induction medium contains serum, cells in spheroids started to migrate out and attach to the culture surface. After 3 weeks, calcium accumulated in both pulp cells from spheroids and in those from monolayer culture was stained by Alizarin Red (Figure 5). No difference was detected between the two groups. Since the migration of cells from spheroids was not complete after 3 weeks, some cell aggregates were still visible and were non-specifically stained with Alizarin Red.

Two weeks after differentiation to adipose tissue, large amounts of lipid droplets were observed in cells from the spheroids and from the monolayers as revealed by staining with Oil Red O. No difference was detected between the two groups of cells. As in the case of osteogenic differentiation, cells aggregates were non-specifically and strongly stained with oil red o (Figure 6).

\section{Discussion}

Factors influencing spheroid formation. From the results of this research, we can conclude that factors influencing spheroid formation of human DPCs include 1) donor teeth, 2) concentration of the KSR, 3) seeding density of the cells. By contrast, freezing/thawing and passaging up to passage 6 do not seem to influence spheroid formation capability.

Since the number of included teeth is very small, no detailed analysis can be carried out to examine possible demographic and medical parameters of the donors (e.g., age, 


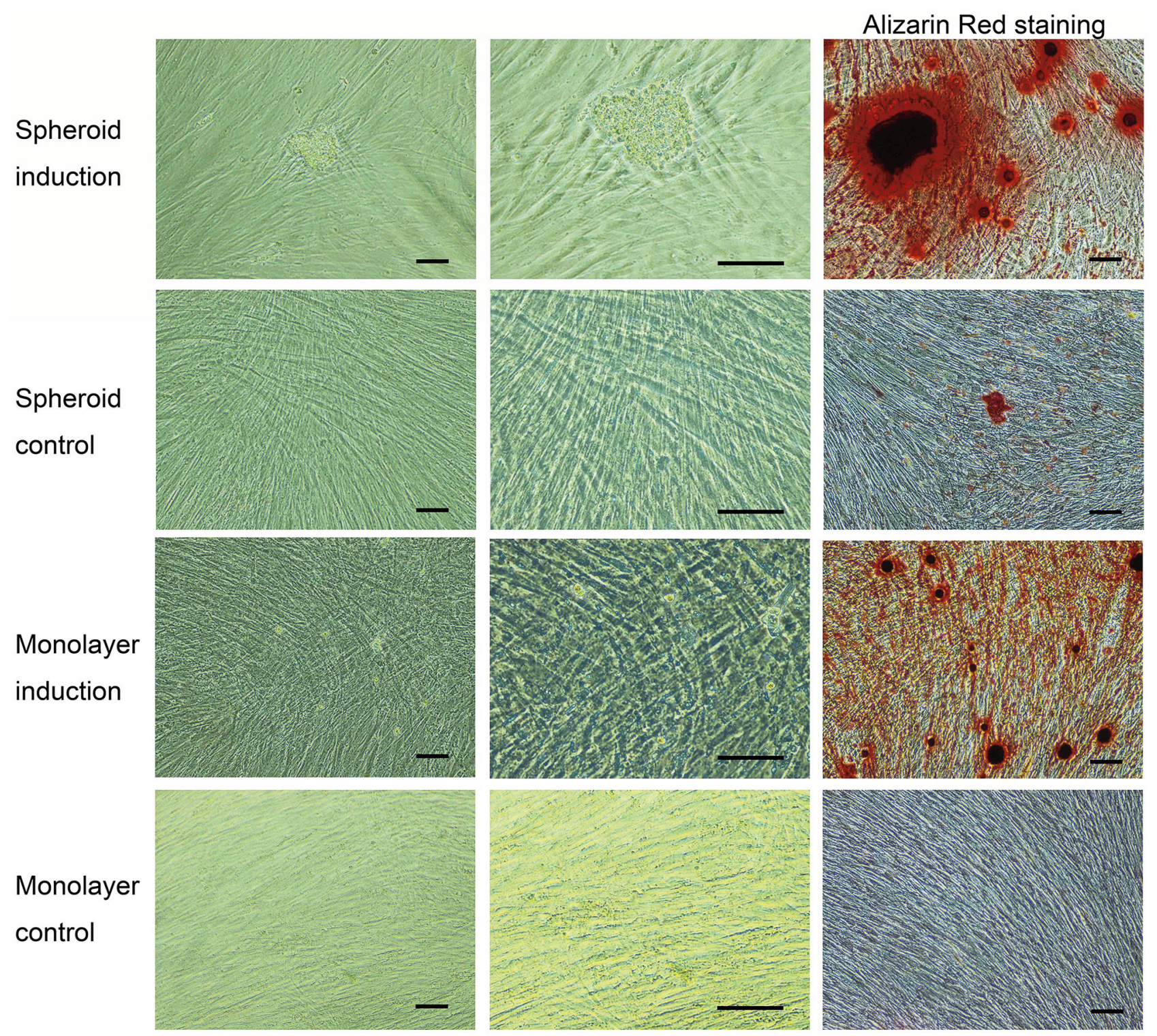

Figure 5. Osteogenic differentiation of dental pulp cells in spheroids or monolayer. Alizarin Red stained calcium sediments in cells from spheroids and cells from monolayer. No obvious difference is visible between the two groups of cells. Scale bars=100 $\mu \mathrm{m}$.

gender, health condition) and donor teeth which may correlate with spheroid formation. Also, the time between the tooth extraction and the setting up of culture in the laboratory may play a role in the viability of the cells and eventually also influence the potential of the cells to form spheroids.

The KSR and cell density generally promote spheroid formation. However, too high concentration of the KnockOut and too high cell density can also lead to death or fusion of the spheroids. As a rule, the following parameters can be recommended for an initial setting for spheroids which may be adjusted and optimized according to the results in each case: $10-15 \% \mathrm{KSR}$, seeding density at $1-2 \times 10^{5}$ cells $/ \mathrm{ml}$ and $2 \times 10^{5}$ cells $/ \mathrm{cm}^{2}$.
Differentiation potential. DPCs from spheroids exhibited compatible differentiation potential as cells in monolayer. Our initial hypothesis that spheroid formation may result in enrichment in stem/progenitor cells, which should have higher differentiation potential, was therefore not proved. In the present study, quantification of stained the differentiated cells did not show a difference. Therefore, if there is a difference this should be subtle.

Another pitfall in evaluating the differentiation of cells in spheroids is the artifact in staining because of the incomplete dissociation of spheroids. To assess differentiation within the spheroids, alternative staining methods are needed. For example, staining of sections of 


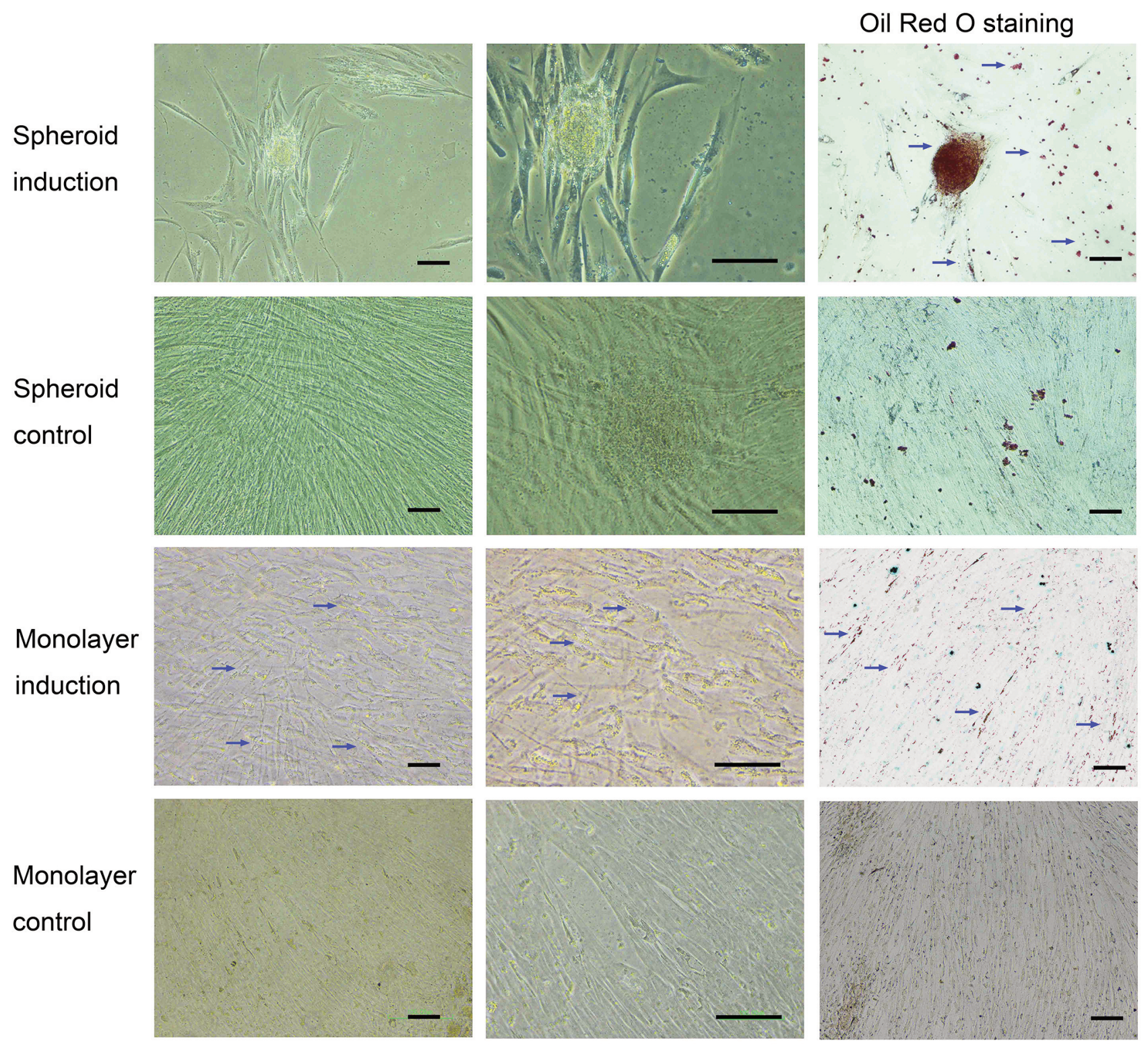

Figure 6. Adipogenic differentiation of dental pulp cells in spheroids and monolayer to adipose tissue. Oil Red O-stained lipid droplets cells from spheroid culture and monolayer (arrows). No obvious difference is visible between the two groups of cells. Scale bars=100 $\mu \mathrm{m}$.

the spheroids may provide an alternative. Also, extensive washing of the dyes out of the aggregates and observation of the stained cells using a confocal microscope may also be a strategy.

Spheroids provide a scaffold-free $3 D$ culture. 3D culture is an advanced cell culture technique especially in regenerative medicine which can be divided into two major categories: scaffold-free and scaffold-based strategies. Spheroid-formation is a scaffold-free 3D culture which corresponds to a multi-cellular organization in vitro. In spheroids, cells assemble themselves in the endogenous extracellular matrix and generate their own microenvironment. Therefore, scaffold-free spheroids provide a $3 \mathrm{D}$ model that more closely reflects the in vivo physiological microenvironment (7). By contrast, scaffolds are generally simple artificial materials, which may influence cell activity in uncertain ways.

In the present study, DPCs formed spheroids without any external physical force. The process is therefore more natural and closer to the process of embryogenesis $(8,9)$. The culture conditions and parameters studied should therefore be valuable for establishing protocols to obtain spheroids that can be further differentiated to various cell lines. 
Serum-free culture. Another advantage of the method used in the present study is the serum-free condition. Usually, the culture media of DPCs are supplemented with fetal calf serum to support cell survival and expansion. However, some contents of serum remain to be unidentified which prevents standardized cell preparations and could transfer pathogens. For clinical applications of stem cells on patients, components of bovine serum may lead to immune responses (10) and result in the rejection of transplanted cells $(10,11)$. Indeed, antibodies against bovine serum proteins have been identified in patients who received cells cultured with calf serum (12). Due to these reasons, it is essential to culture cells under serum-free conditions towards potential clinical use. By contrast, the KSR used in the present study is a supplement with known components and is more suitable for medical applications than bovine serum.

\section{Conclusion}

Donor teeth, the concentration of KSR, and the seeding density are influencing factors for spheroid formation of human DPCs. An initial setting-up can be recommended as serum-free MEM with $10-15 \% \mathrm{KSR}$ at a seeding density of $1-2 \times 10^{5}$ cells $/ \mathrm{ml}$ and $2 \times 10^{5} \mathrm{cells} / \mathrm{cm}^{2}$. Too high KnockOut serum and seeding densities may lead to death and fusion of spheroids. Freezing and thawing did not influence spheroid formation. Subculturing to at least passage 6 did not influence spheroid formation. DPCs in spheroids provide a scaffold-free 3D culture model under the serum-free condition which is desirable for medical applications.

\section{Conflicts of Interest}

The Authors have no conflicting financial interests to declare in relation to this study.

\section{Authors' Contributions}

Yajie Zheng, Li Jiang, and Ming Yan performed the research; Yajie Zheng and Lan Kluwe designed the research study; Ralf Smeets, Lan Kluwe and Reinhard E. Friedrich contributed essential materials or tools; Yajie Zheng wrote the manuscript, Lan Kluwe and Reinhard E. Friedrich revised the manuscript critically.

\section{Acknowledgements}

The Authors thank Mrs. Jane Rehberg for her technical assistance. Y. Zheng and L. Jiang are supported by China Scholarship Council Grant No. 201608080075 and No. 201808080113 , respectively.

\section{References}

1 Nuti N, Corallo C, Chan BM, Ferrari M and Gerami-Naini B: Multipotent differentiation of human dental pulp stem cells: a literature review. Stem Cell Rev Rep 12(5): 511-523, 2016. PMID: 27240827. DOI: 10.1007/s12015-016-9661-9

2 Karaöz E, Demircan PC, Sağlam O, Aksoy A, Kaymaz F and Duruksu G: Human dental pulp stem cells demonstrate better neural and epithelial stem cell properties than bone marrow-derived mesenchymal stem cells. Histochem Cell Biol 136(4): 455-473, 2011. PMID: 21879347. DOI: 10.1007/s00418-011-0858-3

3 Spath L, Rotilio V, Alessandrini M, Gambara G, De Angelis L, Mancini M, Mitsiadis TA, Vivarelli E, Naro F, Filippini A and Papaccio G: Explant-derived human dental pulp stem cells enhance differentiation and proliferation potentials. J Cell Mol Med 14(6B): 1635-1644, 2010. PMID: 19602052. DOI: 10.1111/j.1582-4934.2009.00848.x

4 Xiao L and Tsutsui T: Characterization of human dental pulp cells-derived spheroids in serum-free medium: stem cells in the core. J Cell Biochem 114(11): 2624-2636, 2013. PMID: 23794488. DOI: $10.1002 / \mathrm{jcb} .24610$

5 Spyra M, Kluwe L, Hagel C, Nguyen R, Panse J, Kurtz A, Mautner VF, Rabkin SD and Demestre M: Cancer stem cell-like cells derived from malignant peripheral nerve sheath tumors. PLoS One 6(6): e21099, 2011. PMID: 21695156. DOI: 10.1371/journal.pone.0021099

6 Frahm S, Mautner VF, Brems H, Legius E, Debiec-Rychter M, Friedrich RE, Knöfel WT, Peiper M and Kluwe L: Genetic and phenotypic characterization of tumor cells derived from malignant peripheral nerve sheath tumors of neurofibromatosis type 1 patients. Neurobiol Dis 16(1): 85-91, 2004. PMID: 15207265. DOI: 10.1016/j.nbd.2004.01.006

7 Zhang S, Buttler-Buecher P, Denecke B, Arana-Chavez VE and Apel $\mathrm{C}$ : A comprehensive analysis of human dental pulp cell spheroids in a three-dimensional pellet culture system. Arch Oral Biol 91: 1-8, 2018. PMID: 29621667. DOI: 10.1016/j.archoralbio.2018.02.008

8 Duguay D, Foty RA and Steinberg MS: Cadherin-mediated cell adhesion and tissue segregation: qualitative and quantitative determinants. Dev Biol 253(2): 309-323, 2003. PMID: 12645933. DOI: 10.1016/s0012-1606(02)00016-7

9 Foty RA, Pfleger CM, Forgacs G and Steinberg MS: Surface tensions of embryonic tissues predict their mutual envelopment behavior. Development 122(5): 1611-1620, 1996. PMID: 8625847.

10 Spees JL, Gregory CA, Singh H, Tucker HA, Peister A, Lynch PJ, Hsu SC, Smith J and Prockop DJ: Internalized antigens must be removed to prepare hypoimmunogenic mesenchymal stem cells for cell and gene therapy. Mol Ther 9(5): 747-756, 2004. PMID: 15120336. DOI: 10.1016/j.ymthe.2004.02.012

11 Gregory CA, Reyes E, Whitney MJ and Spees JL: Enhanced engraftment of mesenchymal stem cells in a cutaneous wound model by culture in allogenic species-specific serum and administration in fibrin constructs. Stem Cells 24(10): 2232-2243, 2006. PMID: 16763199. DOI: 10.1634/stemcells.2005-0612

12 Horwitz EM, Gordon PL, Koo WK, Marx JC, Neel MD, McNall RY, Muul L and Hofmann T: Isolated allogeneic bone marrowderived mesenchymal cells engraft and stimulate growth in children with osteogenesis imperfecta: Implications for cell therapy of bone. Proc Natl Acad Sci U.S.A. 99(13): 8932-8937, 2002. PMID: 12084934. DOI: 10.1073/pnas.132252399 